\title{
Frank Netter's legacy
}

\author{
Rafael Romero Reverón * \\ Human Anatomy Department, 7.M. Vargas School of Medicine, Universidad Central de Venezuela, Caracas, Venezuela
}

\begin{abstract}
During a career spanning over 50 years, Dr. Frank Netter (1906-1991) created more than 4,000 medical illustrations. His work helped us advance in our comprehension of human anatomy more than any other medical illustrator, since Vesalius in the sixteenth century.
\end{abstract}

Keywords: Frank Netter; history of medicine; human anatomy; medical illustrations

Anatomy 2014;8:32-35, (C) 2014 TSACA

\section{Introduction}

Human anatomy is the language of medicine, because everything in medicine is related to the human body and the functions of its parts and organs. The purpose of this paper is to show and highlight the contributions by Frank Netter, through his innovative illustrations, to the teaching and learning of human anatomy. As professor of the subject of human anatomy at the J.M. Vargas Medical School, Faculty of Medicine of the Central University of Venezuela and as member of the Venezuelan Society of Medical History, I became interested in investigating and compiling all the available information in order to write this paper on certain aspects of interest regarding the life and work of Frank Netter.

Even though for some authors the study of human anatomy began with the ancient Egyptians and later on with the Greeks, others hark it back to ancient China. Nevertheless, the art of medical illustration did not have staying power until the Renaissance, when artists such as Leonardo Da Vinci and Michael Angelo created drawings based on the dissection of corpses. Later on, in the sixteenth century, with the publication of De Humani Corporis Fabrica in 1543 -a collaboration between physician-anatomist Andreas Vesalius and an artist from
Flanders named Stefan van Kalkar- did this De Fabrica publication become the standard atlas of anatomy for centuries, only to be enhanced or o supplanted by technological discoveries such as the invention of the microscope in the seventeenth century or the discovery of $\mathrm{X}$ rays in the nineteenth century, which revealed new paths into human anatomy.

With a trajectory of over 50 years, Dr. Netter's medical illustrations are standard reference material in the libraries of medical schools all over the world. Among many medical breakthroughs of the twentieth century, his work has documented the first illustrations based on computerized axial tomography images as well as the first artificial heart transplant procedure. Dr. Frank Netter continued solidly in the tradition of this union between science and art. He helped us advance in our comprehension of human anatomy more than any other medical illustrator since the sixteenth century, when Andreas Vesalius introduced drawings based on the dissection of human corpses.

\section{Childhood and Education}

Frank Henry Netter was born on April 25, 1906 in Brooklyn, New York, United States of America. His fam-

\footnotetext{
*Numerary Member of the Venezuelan Society of the History of Medicine; Member of the International Society of the History of Medicine, Member of the American Association of the History of Medicine; Medical Doctor, Specialist in Orthopedic Trauma Surgery at the Centro Médico Docente La Trinidad and Urológico San Román, Caracas, Venezuela
} 
ily was originating from Alsatian, France and Frank Netter father's came from France to New York City in 1895. From an early age, he became interested in art. As a child growing up in New York, he preferred visits to the Metropolitan Museum of Art to playing baseball with other kids and spent his time observing the paintings by Velásquez and other masters. While his fascination with the human form increased, he began to observe in detail what people looked like, how they moved and how they carried their bodies. His capacity for capturing these physical nuances later became the signature of his artwork. ${ }^{[1]}$ While his father supported his passion of art and drawing, Frank Netter's becoming an artist did not meet with his mother's approval. Frank Netter studied at the National Academy of Design and the League of Art Students and by the mid-nineteen twenties he had become a commercial artist working for The Saturday Evening Post and The New York Times. Netter had already established himself as an accomplished commercial artist in the 20's when, on the advice of his mother, he switched careers to find a more "reliable" career.

\section{Becoming a Medical Doctor}

Upon the passing away of his mother, Frank Netter resolute to honor her memory by enrolling in the school of medicine at New York University, where he received his degree in doctor of medicine in 1931 and completed his surgery residency at Bellevue Hospital in 1933. During his studies and training as a surgeon, Netter found that it was easier for him to draw than to take notes in which words were not sufficient. To this respect, Netter commented "My notebooks were chock-full of illustrations. It was the only way for me to recall all of it". During his years as a student, the sketches in his notebooks came to the attention of several medical professors, enabling him to pay his rent and tuition by illustrating conferences, articles and medical text books. ${ }^{[2]}$ The result was Netter's legendary capacity for fully comprehending as a medic before releasing his powerful creative forces as an artist. When he concluded his medical studies in 1931 he started a private surgical practice in Manhattan, New York. But it was the time of the great depression in the U.S., it was the 30's and even surgeries were few and far between.

\section{Choosing Medical Illustration as his Professional Career}

Dr. Netter continued paying his rent thanks to being a medical illustrator and soon his surgical practice dwindled. This was a time when the pharmaceutical industry was transforming the field of medicine through the development of new medicines that changed clinical practice. The leaders in the industry were seeking ways to convey information about these new drugs to the medical profession. The association between Dr. Netter and the pharmaceutical products at the time under the Ciba trademark began in 1936. In 1938, Ciba employed Dr. Netter to work on an ad campaign for heart medication. He designed a heart-shaped folder that was sent to the doctors. Astonishingly, many of the doctors wrote back requesting more heart illustrations without the advertising copy. Netter focused on designing similar ads for products representing other organs and they were all extremely well received. During World War II, as a U.S. army officer, he illustrated several first aid manuals for combat troops on hygienic conditions in the field and survival in tropical areas. At the end of World War II, Netter was commissioned to prepare small folders with illustrations of pathologies later collected in the first Ciba collection of medical illustrations. Frank Netter said "Medical illustration have three main functions: First it to helps the student or physician who is studying a subject to clarify in his own mind. As he sketches he is aided in forming a mental image of the subject. In this sense the hand cooperates with the brain. Second, it helps to transmit our ideas to others, as in a lecture, in a private conversation or in a conference or even in a published article. We transfer the mental image that we have via the paper to the main of another. Third, it serves to preserve ideas for posterity- as in a book or any other publication". ${ }^{[3]}$

\section{His Career and Works}

In 1948, Dr. Frank H. Netter was commissioned by Ciba to create the Ciba-Geigy collection of medical illustrations, a system-by-system encyclopedic series of a dozen volumes on the anatomy, physiology, pathology and histology of the human body and pertinent clinical characteristics of diseases which could appear in each system, the nervous system, the reproductive system, the digestive system, the liver, gall bladder and pancreas, the endocrine system, the kidney, ureters, the bladder, the respiratory system and the musculoskeletal system, thousands of medical illustrations, which became the much consulted Ciba collection of medical illustrations (13 volumes). Netter consulted dozens of medical experts throughout his career during the creation of his paintings, especially for design projects documenting new medical breakthroughs, such as computerized axial tomography, the replacement of common organs and the first artificial heart transplant. Always drawing on the complexity and diversity in the human race, Netter 
strived to create faces and bodies in his work that would reflect individual personalities. The result was that disease and trauma would be viewed in a human light. Netter's sense of humanity and empathy towards patients is one of the characteristics that distinguish his production, more than in other medical illustrators; as he himself stated "I always attempted to make [of the topic] a live patient, with the appropriate facial expression facial and so on and so forth to show that this is not a machine we are dealing with but a patient. ${ }^{[4]}$ Netter spent much more time researching a topic and planning an illustration than executing it. After absorbing as much information as was necessary from multiple sources, he would typically create pencil sketches that would later be copied and transformed into designs in watercolor to which he would often add opaque paint, colored pencils or pastels to create shadows and fine details ${ }^{[5]}$ (Figure 1). In 1966 Netter was awarded the University of New York City Townsend Harris Medal. In 1969, the American Medical Association distinguished him with the Harold Swanberg Medal for Service and in 1973 he received the Medal for Service from the U.S. National Writers' Foundation. He had observed and illustrated open heart surgery, the transplant of organs and common organ replacements. Netter traveled extensively to learn firsthand about a variety of diseases and their effects on the human body. In 1979, Netter was awarded the Kidney Grant, the Resolution of Eulogy, by the legislature of Florida State. In 1980 Dr. William Devries asked Dr. Netter to be present at the first artificial heart transplant that was ever performed, a procedure which Netter illustrated in glorious detail. In 1981, Frank Netter obtained an honorary B.Sc. degree from the faculties of Medicine and Odontology of New Jersey University and also the

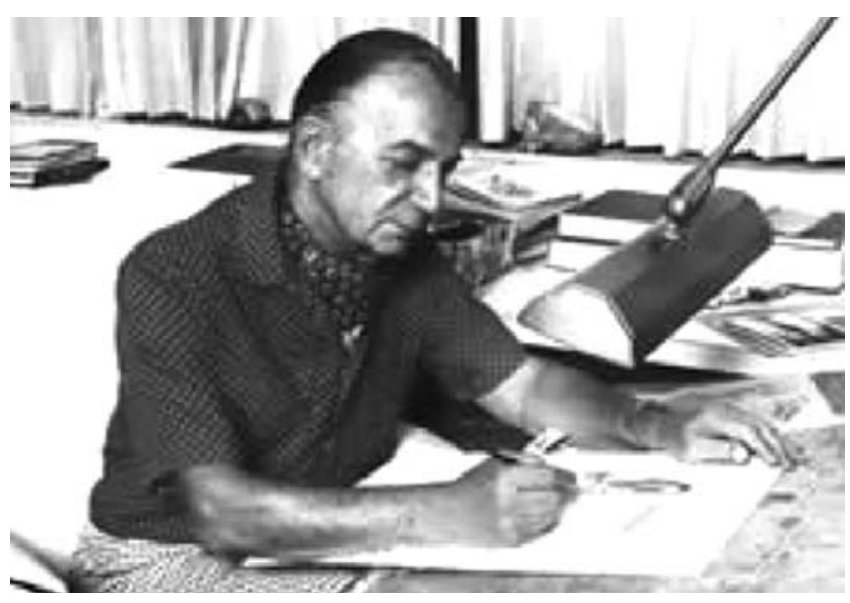

Figure 1. Dr. Frank H. Netter and his pencil sketches. ${ }^{\left[{ }^{[6]}\right.}$ medal for service from the American Cardiology University. Dr. Netter also developed a variety of unusual medical art projects, including the construction of the "transparent female" for the expo in San Francisco's Golden Gate, representing the menstrual cycle, the development and birth of a baby and the physical and sexual development in women. Netter received an honorary degree in science from New York University in 1985.

When asked if he regretted not having continued his surgical practice, Dr. Netter responded that he thought of himself as a clinical doctor with a specialization that encompassed all of medicine: "My field encompassed it all. I have to be a specialist in every field; I have to be able to speak with all doctors in their own terms". In 1986, he was awarded a Lifetime Achievement medal by the Georgetown Society of Illustrators, the medal for accomplishments from the students of the Salomon A. Berson School of Medicine of New York University, an honorary B.Sc. degree from Canada's Sherbrooke University, the Lifetime Achievement medal from the Association of Medical Illustrators and the Honorary medal from the Netter Library of the CIBA-Geigy Corporation. In 1987, he was named an honorary member of the Radiological Society of North America.

Dr. Netter's fabulous capacity for visualizing and simplifying the complex structures and regions of human anatomy are best exemplified in his human anatomy atlas, a fabulous easy-to-understand compendium with marvellous illustrations, easy to learn from a purely academic standpoint but which are also admirable as artistic illustrations. In 1988, Netter was deemed by the New York Times an artist that has contributed probably more to medical education than the majority of the world's anatomy professors taken as a whole. According to experts, Dr. Netter's work is considered to be "the most perfectly executed program possible at the promotional service of medicine". In 1988, he was awarded an honorary medal for his contribution to knowledge of the musculoskeletal system by the American Academy of Orthopedic Surgeons.

While the Ciba collection of medical illustrations is a significant contribution to the study of anatomy, in 1989, Dr. Netter considered the atlas of human anatomy his crowning glory. The atlas rapidly became the most extensively used anatomy atlas in medical schools worldwide and is currently published in 16 languages. Netter's anatomy is currently the first choice among medical and healthcare professionals worldwide. ${ }^{[7]}$ In 1948 Ciba became the Ciba-Geigy Corporation, which merged with Sandoz in January 1997 and became Novartis. In July 2000, Novartis 
sold the rights to Dr. Netter's work to Havas MediMedia and its subsidiary Icon. In August 2005, the rights were sold by Icon to the Elsevier publishing house. In 1990, Dr. Netter was awarded with an honorary grant from the Medical Association of Great Britain Artists and a special recognition from the Association of Medical Illustrators. In 1991 he was named an honorary member of the American Association of Clinical Anatomists.

Netter married twice and had five children and eight grandchildren. He first and foremost was a humanist, who loved life, enjoyed his simple entertainments as playing golf, and afternoon cocktails and cigars. Dr. Frank Henry Netter, after being in the hospital for the last 11 months of his life, passed away in New York on September 17, 1991 at 85 years of age.$^{[8]}$ Among his major disciples are doctors and graphic artists such as Dr. Carlos Machado and Dr. John Craig and David Mascaro, who continue his work in the Netter's style. ${ }^{[9]}$

\section{Discussion}

Dr. Frank Netter is probably the most accomplished and most influential medical illustrator of the 20th century. He produced more than 4,000 paintings of human anatomy, physiology and pathology, as well as illustrations on emerging medical breakthroughs which took place during the course of his life. ${ }^{[6]}$ Frank Netter's work is a practical reference and an amazing tool for medical students and physicians of all specialties wishing to become more familiarized with the anatomy of the human body. He has significantly advanced our comprehension of human anatomy. Netter's legacy represents a major contribution to the teaching and learning of human anatomy in the twentieth century, which continues in the twenty-first century, since his works live on in books, illustrations, drawings and electronic products published that enlighten millions of healthcare professionals throughout the world.

\section{References}

1. Hansen JT, Lambert DR. Netter's Clinical Anatomy. Carlstadt: Icon Learning Systems; 2005.

2. The BioArt of Frank H Netter, MD. 2005. http://www.usciences. edu/museum/netter.shtml

3. Netter F. Medical illustration. Its history, significance and practice. Bull NY Acad Med 1957;33:357-68.

4. Hansen JT. Frank H. Netter, M.D. (1906-1991): The artist and his legacy. Clin Anat 2006;19:481-6.

5. Washko R. Frank H Netter, Medicine's Michelangelo: an editorial perspective. Sci Ed 2006;29:16-8.

6. Frank Netter, MD. (1906-1991). 2005. http://www.netterimages. com/artist/netter.htm

7. Romero R. Dr. Frank Netter: Artista de la anatomía humana. Rev Soc Ven Cien Morf 2007;13:18-20.

8. Netter FM. Medicine's Michelangelo. The Life and Art of Frank H. Netter, MD. Connecticut: Quinnipiac University Press; 2013.

9. Hansen JT. Netter's Anatomy Coloring Book. Philadelphia: Saunders Elsevier; 2010. 